\title{
A INTERPELAÇÃO INTERDISCIPLINAR NA CLÍNICA PSICOPEDAGÓGICA'
}

\author{
EVELYN LEVY \\ TRADUÇĀO: DANIELA W. TEPERMAN
}

Em outra oportunidade, defendi a tese de que a posição do psicopedagogo, em relaf̧ão aos diferentes discursos implicados nas dificuldades de aprendizagem, incide na relação significaşão-intervenção que conduz sua estratégia terapêutica (Levy,1991). Analisei também os efeitos e as diferenças que as operações de suspensão e omissão dos diferentes discursos têm na intervenção ${ }^{2}$.

Ainda que a necessidade de uma abordagem interdisciplinar seja afirmada por todos os psicopedagogos, suas diversas posições teórico-clínicas evidenciam diferentes maneiras de abordar a problemática relação significação-intervenção.

Ao trabalhar em uma equipe interdisciplinar, comprovei que, quando as diferentes leituras de um fenômeno clínico são realizadas a partir de uma interpelação na qual os profissionais das diversas especificidades realizam uma abordagem interdisciplinar das formações clínicas, isto incide notoriamente em nossa intervenção pela maneira como modifica nossos referentes clínicos. Ainda que esta seja uma etapa necessária, constatei, no entanto, que é insuficiente para discutir os efeitos da interdisciplina em nossa intervenção. Falar em interdisciplina e interpelação supõe uma posição diferente da ilusão de uma pacífica confluência multidisciplinar que ao mesmo tempo observe o fenômeno clínico.

Quando, a partir de uma posição de autonomia, os diversos discursos abordam as dificuldades de aprendizagem de uma criança, fazem-no a partir do interior de seus referentes teóricos, dentro das margens de uma particular significafãa interdisciplinar. 
Estas diferentes versões sobre as dificuldades de aprendizagem da criança, ao serem propostas a partir do exterior da clínica psicopedagógica - e portanto desconhecerem alguns dos problemas específicos da mes- ma - não podem deslocar-se diretamente para nossa intervenção. Suas contribuições conceituais e clínicas não podem ser conside-radas esgotadas e se faz necessário interpelálas a partir do fenômeno clínico, através de uma abordagem interdisciplinar.

Há alguns anos enfatizei a importância dos referentes clínicos, para conceituar nossa intervenção, pela maneira através da qual interpelam os referentes teóricos implicados (Levy, 1990). Hoje pretendo aprofundar essa afirmação expondo o que denominei interpelaşão interdisciplinar na intervenção psicopedagógica. Esta formulação supõe o início de uma interpelação interdisciplinar no interior do próprio fenômeno clínico.

No decorrer de diversas supervisões comprovei que, se em alguns casos a maneira de acionar a interdisciplina nas estratégias clínicas depende dos tempos de formação de cada psicopedagogo, em outros o foco a priori tem uma significação na intervenção, parece eliminar a interdisciplinaridade afirmada em suas teorizações de partida. É o que ocorre quando observamos operações de omissãoexclusão de algum dos discursos por parte do psicopedagogo ${ }^{3}$. Evidentemente não é fácil fundamentar-se na ausência de harmonia interdisciplinar. Dar estatuto de verdade absoluta às afirmações de um discurso, em detrimento de outro, 
cepção da criança como percepção de... A percepção, portanto, não se dá sem a mediação do outro. Ao inscrever a percepção da criança como percepção de..., o desejo (inconsciente) da mãe expõe a criança a um significante; - o significante de seu desejo incorporado na percepção de... Por esta via, a presença marcante neste processo não é da percepção, mas do significante que inscreve a percepção através da linguagem.

É a linguagem - o Outro que, ao introduzir a fala, recorta o mundo percebido, nomeando os fragmentos deste. $O$ mundo seria uma grande "coisa percebida", ou várias "coisas percebidas", num todo não diferenciado e sem significado, isto é, sem sentido, como puro significante se a linguagem não o recortasse, nomeando-o. $O$ sentido para este significante é dado pela linguagem, que recorta a "coisa" em si dando-lhe um nome, transformando-a em objeto, atribuindo um sentido à "coisa".

Neste processo convivem os movimentos dos sentidos, das percepções enquanto significantes que invadem o sujeito, e os movimentos dos recortes do percebido feitos pela linguagem, (feitos pelo outro), dando sentido ao percebido, significando o percebido através de uma representação deste percebido. O que é percebido por sua vez deixa assim de ser excluvivamente o percebido, e passa a ser o recorte do percebido através da nomeação que este percebido recebe. Quando digo convivem, entendo que estes movimentos não seguem uma sequência linear evolutiva nos moldes de um "desenvolvimento", primeiro um, depois o outro. Esse percurso é o 
percurso do significante, que entre idas e vindas, não parando de se inscrever, produz através de desmontagens e remontagens a construção do psiquismo enquanto representação da "realidade" - a construção do próprio sujeito. Nesse processo, o significante também inscreve os movimentos da inteligência, como uma representação possível do significante recortado pela linguagem, enquanto cognição, conhecimento, cuja base é a percepção.

O ponto nuclear aí é a representação, pois todo esse processo psíquico que se constitui, constitui-se como representação, o tecido no qual se estrutura a subjetividade humana, o sujeito humano como representante de um significante. Através da representação o sujeito se apropria da "realidade" para si, e representa a si próprio para a "realidade". Estrutura nesse percurso sua inteligência, construindo - a como função que opera conjuntamente a objetividade e a subjetividade humana, de tal modo que a expressão humana objetivada manifesta sempre a subjetividade do significante do desejo inconsciente.

Pois a objetivação humana expressa a representação do significante no qual o sujeito encontra as possibilidades de se representar simbolicamente como sujeito. A inteligência então, como estrutura operativa, é construída como representação entrelaçada na articulação entre subjetividade e objetividade; onde a subjetividade se objetiva e a objetividade se subjetiva, articuladas pelo percurso do significante.

A construção dos conhecimentos, portanto, trabalho sinuoso da inteligência, do sujeito epistêmico, ao se produzir, situa-se dentro desta movimentação significante do desejo do outro.

\section{O CONHECIMENTO COMO DESEJO... DO DESEJO DO OUTRO}

O que Piaget deixa de lado é a representação que o sujeito faz de si próprio nas representações conceituais que elabora, nos sistemas que articula, na forma como opera. Pois a representação, mesmo em sua forma mais abstrata, portanto lógica, nunca exclui o sujeito enquanto sujeito que a representa ao assentar aí seus significantes, produzindo para este um sentido. Por este motivo o sujeito constrói o conhecimento como representação; representando-se nas significações que assume. Se o sujeito não se representasse nas construções que produzisse, isto é, não repousasse aí os significantes, não haveria significação, não haveria sentido nas construções que expressam um "não aprender", um "não conhecer".

Dito de outro modo; as construções feitas pelo sujeito expressam sempre um sentido, que ao fim e ao cabo, podem ser sobre o 
desconhecimento... Assim, quaisquer que sejam as construções que o sujeito faça, estas fogem às expectativas do processo consciente, $\mathrm{e}$ sobretudo fogem às expectativas escolares. Essas manifestações expressam a forma possível que o sujeito encontra para se representar, mesmo que através de um tropeço. $\mathrm{Na}$ construção de um tropeço também repousam significantes produzindo um sentido (inconsciente), aparentemente "sem-sentido" consciente. Há uma lógica nessa construção, a lógica do significante, a lógica do inconsciente.Visto dessa maneira, há aí um "aprender" (inconsciente), do "não aprender" consciente. E aí é que se situam as vicissitudes do conhecer...que não seguem uma linearidade evolutiva e padronizável. $\mathrm{E}$, que surpreendem educadores e psicopedagogos presos a uma linearidade evolutiva, padronizada e normativa... Pois, os sentidos articulados na cadeia de significantes não se expressam necessariamente de forma padronizável. A produção do sentido se dá inclusive nos tropeços da aprendizagem, contendo uma mensagem cifrada que requer deciframento pela via do acompanhamento da escuta...

Por que alguém prefere falar de "terra" na sociologia e não na geologia, se ambas estão à disposição do sujeito na cultura? Possivelmente porque este sujeito sente-se mais representado falando de "terra" na sociologia... E mesmo aí, "terra" tem uma significação particular para cada sujeito...,pois aí repousam significantes inconscientes da singularidade do desejo. Isto faz com que a "terra" na sociologia, para este sujeito, torne-se objeto de conhecimento, ou seja, faz com que este sujeito se objetive, simbolize em algumas produções neste objeto de conhecimento "terra" seus significantes inconscientes.

Este processo nos remete a outro, que diz respeito ao processo no qual o sujeito se representa, representando para si os significados dos objetos de conhecimento. Dito de outro modo, o que faz com que o sujeito tome alguns objetos da cultura para seu conhecimento e não outros? O que faz com que a criança aprenda certos conceitos e não outros, dado principalmente que ela manifesta a possibilidade, (aparente-consciente), destas aprendizagens?

Como acompanhar esta estruturação?

Vamos fazer um percurso que nos parece possível, tomando como base o Estádio do Espelho proposto por Lacan. Através deste, podemos saber que a criança se estrutura no desejo do outro (mãe). Assim, a direção que a criança percorre para conhecer é aquela indicada pelo desejo, (inconsciente), do outro que a constitui, na posição em que está inscrita em relação a esse desejo.

Essa relação é importante porque constitui a criança nesse desejo da mãe, tornando-a investida de desejo (da mãe), investida dos significados dados pela mãe que suportam os significantes que nela se inscrevem. A criança assim investida vai desejar o 
objeto de desejo da mãe, e a própria mãe como seu objeto, porque está identificada com a mãe, sustentando-se nos significantes que esta lhe oferece e significa. É por isso que os objetos do desejo, e aqui poderíamos situar, objetos também do conhecimento, são possíveis de aquisição para a criança, na medida em que forem objetos de desejo/conhecimento da mãe.

Isto se considerarmos que a criança se posiciona de modo direto em relação ao desejo da mãe, o que é uma simplificação do movimento. A criança pode se posicionar de diferentes modos, por exemplo, negando o desejo da mãe. De qualquer maneira a referência para ela constituir seu desejo é a posição que ocupa em relação ao desejo do outro (mãe).

A criança como falo da mãe está assujeitada ao desejo do outromãe, que a estrutura enquanto semelhante a ela. No fundo esta relação é que constitui a ontogênese da criança; pois, a posição da criança espelhando-se na imagem do outro faz com que ela se reconheça no outro (mãe), como humano, e ao outro como semelhante humano. Assim, ao nascer, a criança está envolvida no mundo dos significantes, e o sentido inicial para estes significantes, ou seja, o suporte inicial para sua significação, é dado pelo desejo da mãe através da linguagem. A linguagem da mãe recorta estes significantes atribuindo-lhes sentido. Nesta armação, ou rede inicial, a criança se estrutura no desejo do outro, por uma operação da função materna, estabelecendo um laço social, sua relação como humano no mundo humano, com seus 
semelhantes.

A mãe representa para a criança, TUDO. Completude. Nada lhe falta que a mãe não possa suprir. Não há nada fora da mãe, a mãe responde a todas necessidades da criança, e nada lhe falta. A mãe assim posta constitui a subjetividade da criança. A criança é o falo imaginário do desejo da mãe, e esta - a mãe - é o falo imaginário da criança. Falo considerado como a representação construída com base nessa parte anatômica do corpo do homem" (Nasio, 1988). A presença e ausência do falo inscrevem psiquicamente as diferenças sexuais. Quando a mãe se apresenta como falo da criança e esta como falo da mãe, as diferenças sexuais se anulam porque nenhuma delas deixa de ter o falo. Ambas, uma através da outra, têm o falo; o que as envolve numa relação de completude, de totalidade, uma vez que nada lhes falta. Então aqui não há falta. Ter o falo assume o sentido de que não há falta, ou perda, pois um se complementa no outro como se fossem o mesmo; segundo uma imagem espelhada. E está aí o sentido do imaginário, dado que as relações acontecem aqui pelo espelhamento de um no outro, pela via das imagens.

\section{O CONHECIMENTO COMO (RE) CONS- TRUÇÃO NA METÁFO- RA PATERNA}

Mas algo acontece que impede que esta mãe seja tudo para a criança...; - a castração materna, 
segundo Freud, e portanto a castração na criança.

Ao vivenciar a situação edipiana e a castração, a relação da criança com a mãe sofre um corte, a unidade entre mãe e filho se rompe. A criança deixa de ser o falo da mãe e a mãe deixa de ter na criança seu falo. É introduzida a FALTA, A PERDA. Este corte acontece pela intervenção da função paterna que interdita o incesto, o investimento pulsional exclusivo de um para outro.

A castração entra no desejo fálico da mãe quando seu desejo é submetido a algo que lhe é exterior, que não depende dela; quando, ao falar, esta mãe se remete a um Outro além dela, ao qual pode referir seu discurso - ao Outro, à linguagem. Para discursar, a mãe remete-se às leis da gramática, que independem dela, pertencem ao código da linguagem a que ela está submetida e que está ordenado no sentido de atribuir um lugar, o de mãe. O lugar mãe é possível se remetido a um Outro lugar - o de Pai, que não é o dela. Se ela não é o pai, e para ser mãe remete-se ao pai, a um Outro que não é ela, há um Outro que lhe falta. Fica então introduzida nela - mãe - a FALTA, ou seja aquilo que ela não é, para poder falar daquilo que é. Assim se introduz a castração materna. Em Nome do Pai é que ela se diz mãe, referindo-se a uma Lei que ela reconhece, para falar quem é o pai, reconhecendo o pai de seu filho e com isto a filiação. $\mathrm{Na}$ medida em que o pai é reconhecido, o filho está posicionado diante dele, e não mais exclusivamente posicionado diante da mãe. A castração fica assim introduzida.

O NOME do Pai é a Lei porque ele introduz, de fora da unidade mãe-criança, $U M$ sentido no qual mãe e criança podem se diferenciar ocupando os lugares dados pela cultura como de mãe e de filho, deixando ambos de ser o mesmo, ou deixando a vivência incestuosa da pulsão que busca o prazer indiscriminadamente. É introduzida com a Lei do Pai uma discriminação - ou seja, um sentido, e para tanto, a indiscriminação é barrada. Nesse sentido o Nome do Pai é Simbólico, pois o sentido é algo que rompe com a natureza, que barra a mãe como "natureza", que pode tudo, fazendo sentido na cultura, na instituição dos laços sociais, dos laços que instituem o parentesco, ou seja, a própria cultura. Em Nome do Pai, a mãe deixa de ser TUDO para a criança, algo lhe falta, de modo que ela busca no OUTRO, ou seja, na cultura. E em última análise a Função Paterna é Simbólica porque o pai só tem lugar na cultura, quando a mãe o nomeia. Diferentemente da mãe que carrega a criança em seu útero, ou seja, na sua natureza.

Com a lei de interdição do incesto, a criança perde seu falo, é castrada dele (mãe). Esta perda, esta ausência, deixa um vazio que promove o desejo...de algo...que venha a ocupar esse lugar, ou seja, a substituição do desejo da mãe pelo Nome do Pai.

A interdição da mãe-falo, enquanto objeto de desejo da criança, instala o vazio e promove o desejo que faz a criança buscar o objeto de seu desejo em outro lugar, (no Outro), distante da mãe, fora desta vivência "natural" de satisfação imediata. 
Aqui se introduz a Metáfora Paterna. A Metáfora, como figura de linguagem, configura a possibilidade de substituir um sentido por outro, produzindo assim um sentido a mais.

A METÁFORA PATERNA é a operação de substituição, no código, do desejo da mãe pelo Nome do Pai, produzindo a significação fálica (Lacan, 1957-1958).

A Metáfora Paterna, inscreve o significante falo como significante da falta, da castração. Assim a Metáfora Paterna possibilita ao significante falo, - da falta, assumir outras significações no campo simbólico (do Outro), por operar substituições em Nome do Pai, isto é, que o Nome do Pai pode ocupar. O objeto de desejo da mãe - a criança como seu falo, sendo barrado em Nome do Pai, marcando a falta, introduz o significante falo como falta, que assim pode ser substituído por outros objetos (da cultura, do Outro), que representem a falta (a castração). O Objeto de desejo da mãe, interditado em Nome do Pai, passa a ser substituido e representado por um sentido, (do Outro), através da Metáfora Paterna que ocupa o lugar do Nome do Pai.

No campo da palavra, inúmeras são as significações possíveis. Se todas são possíveis, como fica nossa compreensão? Ficaria impossível. Através da Metáfora Paterna, a inscrição incessante do significante, ou seja, das inúmeras e variadas possibilidades de significação que se cruzam, pode repousar sua materialidade sobre um sentido - S1. Este sentido articula a cadeia de significantes, S1-S2-S3--; gerando o discurso articulado e compreensível, porque referido a uma Lei que o organiza. Há aqui um ponto de consenso, senão haveria delírio comum. Neste ponto de consenso que a Lei instaura se produz o laço social.

Esta passagem pela castração permite que os significantes possam deslocar-se e deslizar, produzindo representações simbólicas, INSCRIÇÕES NO SIMBÓLICO, (que não são o falo, pois este está interditado, mas que o representem), marcadas pela diferença entre os sexos, que inscreve na cultura homem e mulher. A representação simbólica, dessa maneira, ressignifica a perda do falo (mãe), reconstruindo-a nos objetos da cultura, cujo acesso é permitido à criança. Ao mesmo tempo essa re-construção é sobre um Saber (inconsciente) da sexualidade, recalcado diante da castração, cujo conhecimento busca de modo deslocado re-constituir.

Porém, sabemos da mesma forma que não só o real torna-se enigmático conforme a posição subjetiva em relação ao desejo do Outro, mas que os próprios rodeios dados pela criança na sua empresa de (re)construir um Conhecimento sobre a diferença encontram-se em função das vicissitudes que a mudança de posição implica em si mesma que, aliás, são as vicissitudes não padronizáveis do Édipo.

Nesse sentido, cabe dizer que a (re)construção do conhecimento inerente à diferença sexual entretece-se ou entrelaça-se com a logicidade sui generis que toma conta do processamento do 
Saber, que conduz o sujeito a querer e a não querer saber sobre o desejo, irá estruturando esse processo epistêmico (re)construtivo (Lajonquière, 1993).

Acontece através da Metáfora Paterna uma re-construção do objeto original do desejo, (falomãe), agora impedido. O significante falo requer significados que mantenham o desejo num plano separado da mãe, e assim a estruturação deste sujeito não mais alienado no desejo do outro-mãe. $O$ falo como significante da falta permite permutação com outros objetos... que o signifiquem como Metáfora Paterna; pois é um significante que requer significados. Ao falarmos então das trocas simbólicas do significante falo, estamos nos referindo, portanto ao Falo Simbólico. Lacan diz no Seminário sobre "O Desejo e sua Interpretação":

O falo tem uma função, de equivalência na relação com o objeto: é na proporção de uma certa renúncia do falo que o sujeito entra em posse da pluralidade de objetos que caracteriza o mundo humano. (Lacan, 1958-1959).

Ao transitar no mundo dos objetos humanos, da cultura, (Outro), o sujeito pode reconstruir significados para a perda do objeto imaginário do desejo, (mãe), em objetos que para ele re-signifiquem seu desejo. O que equivale a dizer que neste momento ele pode constituir-se como sujeito do seu desejo, deixando de se constituir no desejo da mãe-outro, alienado de si mesmo. Desse modo, a constituição do sujeito, enquanto sujeito do seu desejo, tarefa para a vida toda, vai se constituindo nos furos que puderem ser feitos na imagem do outro, nos furos que o simbólico 
puder fazer no imaginário, no falo imaginário. $\mathrm{E}$ nestes furos, a troca possível é com os objetos construídos pela cultura, significados pela cultura, e dispostos a ser reconstruídos pelo sujeito produzindo um conhecimento por onde este sujeito re-constrói seu desejo.

Quem possibilita construção de conhecimentos é portanto a Metáfora Paterna. Cada conhecimento construído é conhecimento que ocupa um lugar na metáfora paterna, na qual o sujeito representa seu desejo. Desse modo, o conhecimento é representação conceitual e operativa da "realidade" na medida em que o sujeito representa nele seu desejo ressignificado na Metáfora Paterna. É nesse sentido que o Sujeito Epistêmico está subordinado ao Sujeito do Desejo. É nesse sentido também que esse percurso não é natural, contínuo e evolutivo, como um "desenvolvimento". Ele é constituído no discurso dos laços sociais tendo a castração como mecanismo operador, que introduz a falta, permitindo a montagem de uma armação significante mínima que articula desejo e lei.

\section{CONHECIMENTO \\ COMO MOVIMENTO \\ DA INTELIGÊNCIA \\ ARTICULADO PELO \\ MOVIMENTO DO \\ DESEJO}

A re-construção deste conhecimento é plena de idas e vindas, 
depende da posição do sujeito diante da castração, que é descontínua e imprevisível. A re-construção passa por vicissitudes de rupturas, descontinuidades e desconstruções na medida em que a inscrição no símbólico opera furos na imagem do outro, no imaginário do desejo ou no objeto do desejo idealizado. $\mathrm{O}$ vazio deixado pela castração que institui o desejo é revisitado inúmeras vezes; todas as vezes que o sujeito se reencontra com a perda. $\mathrm{O}$ falo como significante da falta é assim ressignificado muitas vezes entre idas e vindas.

A Metáfora Paterna como suporte do significante paterno (da falta) permite assim construções e reconstruções na aventura do sujeito para representar através dela o seu desejo. Mais uma vez constatamos o rompimento com um processo linear e padronizável de evolução psíquica, ou da inteligência.

O percurso do sujeito constituindo-se como sujeito do desejo na metáfora paterna, movimentando-se pela inscrição incessante do significante da falta, não inclui completude. É o percurso da vida humana e suas vicissitudes reinscrevendo-se no simbólico. Desse modo o conhecimento vai sendo reconstruído como inscrição no simbólico furando as idealizações (espelhamentos) do imaginário e permitindo o sujeito deslizar nos significantes de seu desejo, inscrevendo-os no simbólico da palavra e nas possibilidades de significação que esta comporta como fertilidade da criação humana; mas convivendo a todo momento com o fantasma do imaginário. Neste percurso o sujeito encontra suporte no simbólico da Metáfora Paterna aventurando-se nas vicissitudes da descontinuidade e imprevisibilidade em busca de tornar-se sujeito de seu desejo.

Por sua vez, o movimento da inteligência na reconstrução do conhecimento está inscrito nas possibilidades marcadas pela posição do sujeito diante da castração. A maneira como o sujeito pode se inscrever no simbólico e significar seu desejo na Metáfora Paterna expressa a modalidade em que ele pode re-construir o conhecimento sobre o Saber da sexualidade recalcada. Dito de outro modo, a modalidade de acesso do sujeito ao conhecimento está ligada à sua posição diante da castração. Conforme sua posição são possíveis construções como a sublimação ou construções como os sintomas. $\mathrm{O}$ aprender, enquanto aquisição de conhecimentos, acompanha esta modalidade. Esse percurso é o percurso do significante no qual a aprendizagem está inscrita, articulando o desejo do sujeito a um objeto que por reapresentar o objeto do desejo (recalcado), pode ser ressignificado e reconstruído como objeto de conhecimento, increvendo no simbólico o sujeito do desejo.

A complexidade das ações não responde a uma lógica maturativa, mas sim à tentativa da criança de usar, dispor do significante que o Outro exerce (Jerusalinsky, 1988).

Aqui reescrevemos a concepção de Piaget por outros re- 
gistros, e certamente saimos da teoria de Piaget no strictu sensu. Nesse sentido, a inteligência formal opera maior flexibilidade de pensamento pela via conceitual, movimentando-se entre sistemas de conceitos, produzindo deslocamentos e transformações intercambiáveis dentro de um processo que não é equilibrante, mas sim imprevisível e não padronizável, uma vez que está ancorada no movimento do desejo, ou seja, num movimento que não é dela mas de Outro (inconsciente) que a sustenta. E sua operatividade pode ser exercida na proporção em que a função paterna, que opera a castração, promover, pela via do significante paterno, os furos na imagem do outro. $\mathrm{O}$ objeto de conhecimento é então escavado e extraído no buraco da ausência que promove o desejo... como objeto causa de desejo (objeto a); e por isso é objeto também do conhecimento. E, dado que é na falta, na carência que o desejo se institui, e não no lugar ocupado pela coisa, o sujeito epistêmico sofre continuamente de uma impossibilidade; da falta, da ausência. Dado que o Real, o Imaginário e o Simbólico, lugares por onde desliza o significante, estão entrelaçados, a construção do conhecimento enquanto significação está sempre entrelaçada nestes registros... Quer dizer que os conhecimentos construídos são significações dentro das inúmeras possíveis de se inscreverem; portanto sem completude, uma vez que para ser construído um sentido, ou o objeto do desejo como "um", algo (do Outro) sempre vai lhe faltar...

\section{A PORTA ESTÁ ABERTA....}

$\mathrm{O}$ que isto significa? Significa sobretudo para o "psicopedagogo", para os educadores, e para aqueles que trabalham com a produção e a transmissão do conhecimento - seja lá como queiram se rotular -, uma abertura de possibilidades para penetrar no movimento do desejo e acompanhar como este sustenta e direciona o movimento da inteligência, bem como as perplexidades que este suscita. Podemos nos utilizar da obra piagetiana naquilo em que ela nos remete ao processo específico de funcionamento da inteligência. No entanto esta posição nos conduz também a não permanecermos nos limites da psicologia cognitivista; nos limites da construção epistêmica do sujeito, uma vez que o sujeito não se explica nem se define restritivamente como sujeito epistemológico, e nem pela dupla famosa e interativa entre cognição e afetividade, que reproduz o dualismo cartesiano entre mente e corpo na modernidade.

O sujeito é o sujeito do desejo... com todas as suas dificuldades, complicações.., e magníficas e descontínuas criações! E não adiantaria, como historicamente não adiantou, querermos simpli- 
ficar as confusões ou as "esquisitices" que o sujeito expressa, buscando enquadrá-lo num modelo que o simplifique como o fizeram os funcionalistas e behavioristas, cuja herança permanece até hoje na razão técnica que absorve e pasteuriza concepções mais sofisticadas sobre o sujeito.

Acredito que seria mais interessante acompanhar o movimento difícil e complicado, caprichoso e imprevisível, do desejo...

No entanto, as razões técnicas das metodologias ditas do ensino podem me perguntar, -como se faz isto ? Ou, qual a metodologia?!

Sinto desapontá-las, mas não existe...

Acompanhar o desejo é poder escutá-lo... E não há como escutar o desejo do outro sem que possamos escutar o nosso desejo... Aí é que está a questão!

Escutar o desejo é escutar seu inconsciente nos tropeços $\mathrm{e}$ atos falhos, nos variados sentidos das variadas construções... Escuta o desejo quem se importa em acompanhar a mensagem contida no desvio da normatização...e só...

Assinalamos um caminho onde buscamos a produção de novos conhecimentos deslocados da razão técnica na qual a psicologia se instalou e estagnou levando para a estagnação da repetição a teoria pedagógica e o processo educacional. Nesta busca de novos conhecimentos utilizamos de conceitos de campos específicos. Não se trata de um novo sonho dourado, uma nova idealização, ou um novo modismo. E, muito menos uma justaposição de campos, ou de uma interdisciplinaridade ao gosto dos ecléticos.

Trata-se de utilizar conceitos que permaneceram fechados em 
seus campos e podem ser recortados e reconstruídos à medida que forem colocados num outro campo, onde sua força e vitalidade, reestudadas e pesquisadas, podem ser fertilizadas produzindo articulações já feitas em seus campos de origem, e que podem ser refeitas e revigoradas neste outro campo através de uma reconstrução, ou de uma reinscrição, ampliando o próprio repertório conceitual do campo de origem. Nesse processo o eixo é uma epistemologia da descontinuidade, onde a continuidade de um campo, de uma teoria, é rompida na interlocução com outro campo ou teoria, operando aí o recorte quando ambos olham para a mesma temática que os chamou para o diálogo. Esta descontinuidade que a interlocução introduz marca a possibilidade de um percurso antipositivista com grandes chances de romper a razão técnica e seu projeto normatizador.

Aqui o recorte trata da construção da psicopedagogia no seio de sua práxis clínica, que por ser clínica no sentido de acompanhar o percurso particular do desejo, se constitui como escuta do desejo de Saber (inconsciente) do sujeito, que se expressa em seu estilo de Conhecer (consciente), inscrito nas vicissitudes do aprender, portanto não padronizáveis.

\section{REFERÊNCIAS BIBLIOGRÁFICAS}

BERGÈs, J.A. O corpo e o olhar do outro. Porto Alegre, Cooperativa Jacques Lacan, 1988.

a BERGÈS, J.A. A instância da letra na aprendizagem. Boletim da Associação de Porto Alegre, n.6, 1991. 
BERGÈS, J.A. -B-. In: Escritos da Criança. Porto Alegre, Centro Lydia Coriat, 1988. ano 2, n.2. Textos:

Leitura e escrita literais; -Ao pé da escritura; Retardo da linguagem e afetividade; Lesão real e lesão fantasmática; Debilidade e problemas instrumentais; Nota sobre transtornos instrumentais e as desarmonias evolutivas.

- CHULAN, T.M.O. Escritos sobre os escritos de Lacan. Vitória, Fundação Ceciliano Abel de Almeida, 1981.

- FREUD, S. Obras completas. Buenos Aires, Amorrortu, 1989.

- FREUD, S. (1900). La interpretación de los sueños. In: Obras completas. Buenos Aires, Amorrortu, 1989. v.4/5.

FREUD, S. (1901). Psicopatología de la vida cotidiana. In: Obras completas. Buenos Aires, Amorrortu, 1989. v.6.

FREUD, S. (1905a). Tres ensaios de teoria sexual. In: Obras completas. Buenos Aires, Amorrortu, 1989. v.7.

FREUD, S. (1905b). El chiste e su relación con lo inconsciente. In: Obras completas. Buenos Aires, Amorrortu, 1989. v.8.

FREUD, S. (1908a). Análisis de la fobia de un nino de cinco años. In: Obras completas. Buenos Aires, Amorrortu, 1989. v.9.

- FREUD, S. (1908b). Sobre las teorías sexuales infantiles. In: Obras completas. Buenos Aires, Amorrortu, 1989. v.9.

aREUD, S. (1910). Un recuerdo infantil de Leonardo da Vinci. In: Obras completas. Buenos Aires, Amorrortu, 1989. v.11.

- FREUD, S. (1912). Sobre la dinámica de la transferencia. In: Obras completas. Buenos Aires, Amorrortu, 1989, v.12.

FREUD, S. (1914). Recordar, repetir y reelaborar. In: Obras completas. Buenos Aires, Amorrortu, 1989. v.12.

- FREUD, S. (1915a). Pulsiones y destinos de pulsion. In: Obras completas. Buenos Aires, Amorrortu, 1989. v.14.

FREUD, S. (1915b). A repressão. In: Obras completas. Buenos Aires, Amorrortu, 1989. v. 14 .

- FREUD, S. (1915c). O inconsciente. In: Obras completas. Buenos Aires, Amorrortu, 1989. v.14.

- FREUD, S. (1916/1917). Conferencia 27 - La transferencia. In: Obras completas. Buenos Aires, Amorrortu, 1989. v. 16 . 
FREUD, S. (1916/1917). Conferencia 28 - La terapia analítica. In: Obras completas. Buenos Aires, Amorrortu, 1989. v.16.

aREUD, S. (1920). Más allá del princípio de placer. In: Obras completas. Buenos Aires, Amorrortu, 1989. v.18.

- FREUD, S. (1925). Algunas consecuencias psíquicas de la diferencia anatómica entre los sexos. In: Obras completas. Buenos Aires, Amorrortu, 1989. v.19.

- FurTh, H.G. Piaget e o conhecimento. Rio de Janeiro, Forense Universitária, 1974.

- HARARI, R. Uma introdução aos quatro conceitos fundamentais de Lacan. São Paulo, Papirus, 1990.

- Jerusalinsky, A. et. al. Psicanálise e desenvolvimento infantil. Porto Alegre, Artes Médicas, 1988.

- LACAN, J. El Seminario sobre la Carta Robada; - El Estadio del Espejo como formador de la función del yo (je) tal qual nos revela en la experiência psicoanalítica; - Función e Campo de la Palabra y del Lenguage em Psicoanálisis - La Instancia de la Letra en el Inconsciente o la Razón desde Freud; - La Significación del Falo; Subverción del Sujeto y Dialéctica del Deseo en el Inconsciente Freudiano. In: Escritos 1 e 2 . Madrid, Siglo Vientiuni, 1971.

- LACAN, J. Seminário - livro 1: escritos técnicos de Freud. Rio de Janeiro, Jorge Zahar, 1988.

- LACAN, J. Seminário - livro 4: a relação de objeto. Rio de Janeiro, Jorge Zahar, 1995.

LACAN, J. Seminário - livro 6: les formations de l'inconscient, 1957-1958. [inédito]

LACAN, J. Seminário - livro 6: Le desir e son interpretation, 1958-1959. [inédito]

LACAN J. Seminário - livro 11: os quatro conceitos fundamentais. 1988.

- LACAN, J. Shakespeare - Duras Wedewkind - Joyce. Lisboa, Assirio \& Alvim, 1989.

- lajonquière, L. De Piaget a Freud. Petrópolis, Vozes, 1993.

LEMAIRE, A. Jacques Lacan, uma introdução. Rio de Janeiro, Ed. Campus, 1986.

LEVIN, E. O gesto e o outro: o visível e o invisivel. In: Escritos da Criança. Porto Alegre, Centro Lydia Coriat, 1990, ano 3, n. 3.

- MILLOT, C. Freud antipedagogo. Rio de Janeiro, Zahar, 1987.

- NASIO, J.D. Os 7 conceitos cruciais da psicanálise. Rio de Janeiro, Zahar, 1988. 


\section{Artigo}

PALMIER, J.M. Lacan. São Paulo, Melhoramentos, 1977.

ROZA, A. Introdução à metapsicologia Freudiana - 2 - A interpretação dos sonhos (1900). Rio de Janeiro, Jorge Zahar, 1991.

- ROZA, A. Introdução à metapsicologia freudiana - Artigos de metapsicologia (19141918). Rio de Janeiro, Zahar, 1995.

- PIAGET, J. Construção do real na criança. Rio de Janeiro, Zahar, 1979.

- PIAGET, J. Epistemologia genética. In: Problemas de psicologia genética. Sào Paulo, Abril Cultural, 1978.

- PIAGET, J. Equilibração das estruturas cognitivas. Rio de Janeiro, Zahar, 1976.

- PIAGET, J. O estruturalismo. Rio de Janeiro, Difel, 1974.

- PIAGET, J. Formação do símbolo na criança. Rio de Janeiro, Zahar, 1971.

ם PIAGET, J. Psicologia da inteligência. Rio de Janeiro, Editora Fundo de Cultura, 1989.

- PIAGET, J.; GRÉCO. Aprendizagem e conhecimento. Rio de Janeiro, Freitas Bastos, s.d. n PIAget, J.; INHelder, B. Psicologia da Criança. Rio de Janeiro, Ed. Bertrand Brasil, 1989.

\section{NOTAS}

Colocamos realidade entre aspas, para lembrar que realidade é aquela representada pelo significante, e que não estamos nos referindo à realidade em si, pois consideramos que esta é inacessivel 